\title{
Urbanisation and cariogenic food habits among 4-24-month-old black South African children in rural and urban areas
}

\author{
Jennifer M MacKeown ${ }^{1, *}$ and Mieke Faber ${ }^{2}$ \\ ${ }^{1}$ Dental Research Institute, University of the Witwatersrand, Private Bag X03, Wits 2050, Johannesburg, \\ South Africa: ${ }^{2}$ Nutritional Intervention Research Unit (NIRU), South African Medical Research Council, \\ PO Box 19070, Tygerberg 7505, South Africa
}

Submitted 22 March 2002: Accepted 30 May 2002

\begin{abstract}
Objective: To determine if social class, education level and group environment (rural and urban) influence particular food habits commonly associated with dental caries incidence among 4-24-month-old black South African children.

Design, setting and subjects: Information was collected by trained interviewers using a food-frequency questionnaire from mothers of children in two areas in South Africa: Ndunakazi, a rural area in KwaZulu/Natal $(n=105)$ and two urban areas in Gauteng - Soweto (low to middle socio-economic area) $(n=100)$ and the northern suburbs of Johannesburg and Sandton (middle to upper socio-economic area) $(n=101)$. Education level and occupation of the parents, which define social class, were also recorded. A linear logistic (Proc Catmod) analysis tested social class, education level and group environment as the independent variables and the food habits as the dependent variables.

Results: Group environment was significantly associated with nine of the 18 food habits investigated. More urban than rural mothers added sugar to their child's comforter. More mothers in urban Soweto than in urban Johannesburg were still breast-feeding their infants at 24 months. More rural than urban mothers were giving 'mutis' (common and traditional medicines). Together with group environment, education level was significantly associated with giving of 'mutis' and the frequency of giving them. Social class was significantly associated with the frequency of breastfeeding and when the child was breast-fed. Mothers from the upper social class breast-fed less frequently than mothers from the lower class.

Conclusion: The study showed a strong influence of rural/urban environment on specific cariogenic food habits among young black South African children, enabling the development and implementation of a nutrition strategy.
\end{abstract}

It has been suggested that definitions of the urban environment tend to consider only the physical, and not the social complexity of the urban setting ${ }^{1}$. Researchers need to define what is meant by urban so that their studies can be compared with other areas and with the same area over time. Several criteria have been used to describe what is urban and what is rural. The Concise Oxford Dictionary ${ }^{2}$ gives only a broad definition of urban as living or situated in a city or town'. A quantitative definition such as the World Health Organization's (WHO) one of '20000 people'3 ignores qualitative differences between urban areas. Van de Graaf $^{4}$ proposed a number of other criteria which include the form of administration present in the area, density (people per $\mathrm{km}^{2}$ ), economic function (agricultural versus industrial) and access to basic services. It is important, however, to be aware of the limitations of using any single criterion, as it may give rise to stylised conceptions of what constitutes urban living. Rather, the definition used should be determined by the aim of a particular study ${ }^{5}$.

Urbanisation is the movement of people from rural to urban areas. The process of urbanisation could be described as one of the major global environmental changes directly affecting human health today. Populations particularly affected are in developing countries, such as South Africa, where rapid urban growth has been accompanied by massive urban poverty ${ }^{1}$.

Urbanisation provides a unique opportunity to study the effect of complex societal changes, including rapid population increase and concentration, movement from rural to urban areas, circulation within greater urban areas and improved access to employment and education as well as food habits. These changes have had both 
beneficial and adverse effects on health ${ }^{5}$. South Africa is part of these global environmental changes.

South Africa is a land of contrasts, even with regard to caries rates between groups ${ }^{6}$. Climatic, geographic and socio-political circumstances differ and, in the latter context, communities vary from Third to First World with distinct cultural differences for infant feeding and diet as well as dietary habits, often modified by economic factors ${ }^{7}$ and urbanisation. The differences in breast-feeding, for instance, between South African rural and urban black communities indicated the influence of urbanisation on feeding practices as early as 1985. This influence, together with other socio-economic variables, has become more important in the new South Africa, as social barriers to population movement have disappeared ${ }^{7}$ and urbanisation has increased at an exceptionally high rate ${ }^{8}$. Forty per cent of the population of the Third World was urban at the end of the 20th century ${ }^{9,10}$, and this is estimated to increase to $57 \%$ by $2025^{9}$. Considerable attempts have been made in developing countries to restrict, redirect or control the rate of urbanisation. These measures have largely failed and unprecedented growth of urban populations continues ${ }^{5}$.

Epidemiological research needs to focus on understanding the relationship between changes that occur during urbanisation and their impact on health ${ }^{5}$. With the exception of Nigeria $^{11}$, African countries have not investigated systematically the health issues surrounding urbanisation $^{12}$. It has been suggested that the effect of urbanisation on the cariogenic dietary habits of South African children be investigated ${ }^{7}$.

Critical evaluation of published information showed that there is no scientific proof that cariogenic foods have either increased or decreased as a result of urbanisation in developing or developed countries. However, there are claims from outside South Africa that the level of urbanisation affects most nutrients ${ }^{13}$. Social, demographic and lifestyle factors relating to the mother have been shown to influence the early eating patterns of children ${ }^{14}$. Information on the influence of urbanisation on cariogenic food habits is lacking and reliable information among young South African children needs to be established.

Since the South African government (through the National Department of Health) is committed to develop and implement an integrated nutrition strategy targeting children $^{15}$, the identification and recognition of the effects of urbanisation and other socio-economic factors on the eating habits of infants and young children is very important.

The objective of this study was to determine if social class, education level and group environment (rural/urban) influenced particular food habits commonly associated with dental caries incidence among 4-24-month-old black South African children. A future manuscript will discuss the frequency of consumption of the actual cariogenic food items consumed by these children.

\section{Methods}

Ethics approval was obtained from the University of the Witwatersrand Committee for Research on Human Subjects (Medical). Permission was also obtained from the Eastern and Southern Metropolitan Local Councils to visit the relevant clinics. All parents gave verbal consent before participating in the study.

\section{Subjects}

The study sample comprised South African children aged 4-24 months from three black communities. The study areas included (1) a rural area of low socio-economic status in KwaZulu/Natal (Ndunakazi), (2) an urban area of low to middle socio-economic status in Gauteng (Soweto), and (3) an urban area of middle to upper socio-economic status in Gauteng (northern suburbs of Johannesburg and Sandton). The average household income in Soweto is up to R30 000 per annum and that in the northern suburbs is above R80000 ${ }^{16}$. Data on household income in the rural area are not available.

\section{Dietary assessment}

A food-frequency questionnaire appropriate for both rural and urban areas was used. It included cariogenic food items usually consumed by children based on previous experience and the principle of fermentable carbohydrates allowing foods to be ranked according to their cariogenic potential $^{17}$. From this principle several dietary habits have been associated with dental caries and 18 of these appropriate for young South African children were used in this study.

The education level and occupation of the parents were recorded to define social class ${ }^{18,19}$, which influences the effects of urbanisation ${ }^{20}$.

In the rural area information was collected from 105 parents who attended community-based growthmonitoring sessions ${ }^{21}$. The mothers were interviewed by nutrition monitors (local people trained specifically to run community-based nutrition projects) in their mother tongue (Zulu). For the urban areas the information was collected by trained interviewers from parents attending Chiawelo Clinic in Soweto $(n=100)$ and the clinics in the Johannesburg/Sandton area $(n=101)$. The interviewers were familiar with the questionnaire, as they had done nutritional fieldwork for the Dental Research Institute on previous occasions. Chiawelo Clinic was chosen as it is centrally situated, easily accessible and serves a wide area of the Soweto community. For the Johannesburg/Sandton area, five clinics (Yeoville, Parkhurst, Orchards, Wendywood and Lyndhurst) were included, representing a wide area of the higher socio-economic sector. 
The data were coded onto computer-coding sheets using the South African Medical Research Council's (MRC) food composition tables and codes $^{22}$.

\section{Statistical analysis}

The data were analysed with $\mathrm{SAS}^{23}$. Linear logistic analysis (Proc Catmod) was used to test if any of the food habits were associated with social class, education level and/or group environment. Independent variables were: (1) social class (two groupings - upper and lower; derived from the occupation of the father or mother, if the father was unemployed, using six British social classes ${ }^{18}$ condensed into two and the South African occupation descriptions ${ }^{19}$ ); (2) education level (three groupings low, where both parents had completed less than 10 years of schooling; middle, where one parent had completed 10-12 years of schooling and the other 7-12 years; and high, where one parent had completed 12 years of schooling plus tertiary education and the other at least 12 years of schooling ${ }^{24}$ ); and (3) group environment (three groupings - 1, rural; 2, urban Soweto; and 3, urban Johannesburg). The dependent variables were the individual food habits.

The first linear logistic analysis used all three of the independent variables; if one variable was significant but another showed redundant or restricted parameters, only the two relevant independent variables were tested with a second linear logistic analysis. This was to see if two of the independent variables showed a more significant association than all three variables together.

Cross-tabulation of social class, education level and group environment with each categorised food habit was done. This gave the percentage and number of individuals in each category of social class, education level and group environment for each food habit.

\section{Results}

With social class, education level and group environment as the independent variables and food habits as the dependent variables, the linear logistic analysis showed group environment to be significantly associated with nine of the 18 dietary habits investigated. These were: the addition of sugar to the child's comforter and the number of times per day this was done, how often the child was put to sleep with a bottle, whether the child was still being breast-fed or not and the length of time the child was breast-fed, the giving of 'mutis' (common and traditional medicines), number of 'mutis' given and the frequency of giving them, and the addition of milk only or milk plus sugar to cereal. Group environment and education level were also significantly associated with giving of 'mutis', the number of 'mutis' given and the frequency of giving them. 'Mutis' is a common term used by the indigenous people of South Africa for common over-the-counter medicines as well as for some traditional home remedies commonly used, and were included in the questionnaire as sugar is often used to sweeten medicines to improve their palatability $^{25}$. Social class was significantly associated with the frequency of breast-feeding and when the child was breast-fed. Details of these variables are given in Tables 1-3. Group environment, education level of the parents and social class were not significantly associated with whether the child was put to sleep with a bottle or not, number of meals eaten per day, age at which breastfeeding stopped, amount of 'mutis' given and whether sugar was added to drinks or formula. These variables have therefore been excluded from the tables.

\section{Sugar use with comforter}

Urbanisation was associated with the use of sugar on comforters (Table 1). Only 5\% of the rural mothers added sugar to their child's comforter. In urban Soweto and Johannesburg, $27 \%$ and 55\%, respectively, added sugar to their child's comforter. With an increase in urbanisation there was an increase in the use of sugar on comforters and the frequency of this habit.

\section{Use of bottle}

In urban Soweto, $82 \%$ indicated that they either never put their child to sleep with a bottle or never used a feeding bottle (Table 1). This was slightly lower for both the rural group and the urban Johannesburg group, being just over $70 \%$.

\section{Breast-feeding}

Only the two urban groups were significantly associated with whether the child was still being breast-fed or not (Tables 1 and 2). Fifty-seven per cent and 38\% of the urban Soweto and urban Johannesburg mothers, respectively, were still breast-feeding their child at 24 months.

Social class was significantly associated with the number of times the child was breast-fed and when the child was breast-fed. Mothers from the upper social class tended to breast-feed $1-3$ times daily (18.4\%) and in the mornings and/or evenings (15.8\%), while mothers from the lower social class breast-fed more frequently (4-7 times daily) (32.4\%) and throughout the day (37.1\%). The majority of mothers from the rural group (84.8\%) did not answer the question 'How long is your child breast-fed for?' as they found it difficult to interpret and to put a time on breastfeeding. For the urban Soweto and Johannesburg groups, most of the mothers who answered breast-fed for 10 minutes or more.

\section{'Mutis' (common and traditional medicines)}

More rural mothers (68\%) than urban mothers (52\% and $56 \%$ in Soweto and Johannesburg, respectively) indicated that they were giving unprescribed 'mutis' at the time (Table 1). The majority of these mothers gave only one 'muti'. Most rural mothers (65\%) indicated that they gave 
Table 1 Summary of significant associations of cariogenic dietary habits with group environment. Values are given as $\%(n)$, where \% is percentage of children and $n$ is number of children

\begin{tabular}{|c|c|c|c|}
\hline \multirow[b]{2}{*}{ Variable } & \multicolumn{3}{|c|}{ Group environment } \\
\hline & Rural & Urban Soweto & Urban Johannesburg \\
\hline \multicolumn{4}{|l|}{ Do you add sugar to your child's comforter? } \\
\hline Yes & $4.8(5)$ & $27.0(27)$ & $54.5(55)$ \\
\hline \multicolumn{4}{|c|}{ Number of times per day sugar is added to comforter } \\
\hline Never & $96.2(101)$ & $74.0(74)$ & $47.5(48)$ \\
\hline Morning/evening & $2.0(2)$ & $16.0(16)$ & $16.8(17)$ \\
\hline Throughout the day & $2.0(2)$ & $10.0(10)$ & $35.6(36)$ \\
\hline \multicolumn{4}{|l|}{ How often is your child put to sleep with a bottle? } \\
\hline Never & $70.5(74)$ & $81.9(77)$ & $72.0(72)$ \\
\hline Frequently & $15.2(16)$ & $9.6(9)$ & $23.0(23)$ \\
\hline Occasionally & $14.3(15)$ & $8.5(8)$ & $5.0(5)$ \\
\hline \multicolumn{4}{|l|}{ Is your child still being breast-fed? } \\
\hline Yes & NS & $57.0(57)$ & $37.6(38)$ \\
\hline \multicolumn{4}{|l|}{ How long is your child breast-fed for? } \\
\hline Never & $84.8(89)$ & $42.0(42)$ & $60.4(61)$ \\
\hline $3-9 \min$ & $11.4(12)$ & $12.0(12)$ & $5.9(6)$ \\
\hline $10 \mathrm{~min}$ & $1.0(1)$ & $23.0(23)$ & $22.8(23)$ \\
\hline$\geq 15 \min$ & $2.9(3)$ & $23.0(23)$ & $10.9(11)$ \\
\hline \multicolumn{4}{|l|}{ Do you give your child 'mutis'? } \\
\hline Yes & $67.6(71)$ & $52.0(52)$ & $56.4(57)$ \\
\hline \multicolumn{4}{|l|}{ Number of 'mutis' given } \\
\hline None & $30.5(32)$ & $49.0(49)$ & $45.5(46)$ \\
\hline 1 & $43.8(46)$ & $31.0(31)$ & $32.7(33)$ \\
\hline 2 & $21.9(23)$ & $12.0(12)$ & $16.8(17)$ \\
\hline$\geq 3$ & $3.8(4)$ & $8.0(8)$ & $5.0(5)$ \\
\hline \multicolumn{4}{|l|}{ How often do you give 'mutis'? } \\
\hline Never & $29.5(31)$ & $63.0(63)$ & $65.4(66)$ \\
\hline Daily/weekly & $4.8(5)$ & $25.0(25)$ & $28.7(29)$ \\
\hline More than once per day or when needed & $65.7(69)$ & $12.0(12)$ & $5.9(6)$ \\
\hline \multicolumn{4}{|l|}{ Do you add milk only or milk plus sugar to cereal? } \\
\hline Milk only & $22.1(23)$ & $9.0(9)$ & $36.7(36)$ \\
\hline Milk plus sugar & $77.9(81)$ & $91.0(91)$ & $63.3(62)$ \\
\hline
\end{tabular}

NS - not significant.

the 'mutis' when needed, while most of the urban mothers gave the 'mutis' daily.

However, with education level being significantly related to 'mutis', it was found that more mothers who had a higher education level tended to give 'mutis' (Table 3). With an increase in education level there was an increase in the percentage of mothers who gave two 'mutis'. Of the mothers giving 'mutis', those with a higher

Table 2 Summary of significant associations of cariogenic dietary habits with social class. Values are given as $\%(n)$, where $\%$ is percentage of children and $n$ is number of children

\begin{tabular}{llr}
\hline & \multicolumn{2}{c}{ Social class } \\
\cline { 2 - 3 } Variable & \multicolumn{1}{c}{1} & \multicolumn{1}{c}{2} \\
\hline Number of times child is breast-fed & $52.4(89)$ \\
Never & $55.3(21)$ & $7.7(13)$ \\
$1-3$ & $18.4(7)$ & $32.2(55)$ \\
$4-7$ & $13.2(5)$ & $7.7(13)$ \\
$\geq 8$ & $13.2(5)$ & $54.1(92)$ \\
When is your child breast-fed? & & $83.2(24)$ \\
$\quad$ Never & $15.8(6)$ & $37.1(63)$ \\
Morning/evening & $21.1(8)$ & \\
Throughout the day & &
\end{tabular}

Social class: 1 - upper; 2 - lower. education level gave them daily, while those with a lower education level gave them when needed.

\section{Sugar use with cereal}

There was a tendency for mothers from all three group environments to add sugar to the child's cereal (Table 1), the highest percentage being in the urban Soweto group (91\%), followed by the rural group (78\%) and finally the urban Johannesburg group (63\%).

\section{Discussion}

\section{Main findings}

The study showed rural/urban environment to be associated with various dietary habits among young South African black children. In addition, social class was significantly associated with breast-feeding and education level was significantly associated with the use of 'mutis'.

\section{Methodology problems}

Studies on the differences between rural and urban dwellers often do not state explicitly which people are included in the rural or urban group. For example, in a cross-sectional study in rapidly changing peri-urban areas, 
Table 3 Summary of significant associations of cariogenic dietary habits with education level. Values are given as $\%(n)$, where $\%$ is percentage of children and $n$ is number of children

\begin{tabular}{lccc}
\hline & \multicolumn{3}{c}{ Education level } \\
\cline { 2 - 4 } Variable & 1 & 2 & 3 \\
\hline Do you give your child any 'mutis'? & & & \\
$\quad$ Yes & $44.9(39)$ & $66.9(109)$ & $65.2(15)$ \\
Number of 'mutis' given & & & $39.1(9)$ \\
$\quad$ Never & $56.3(49)$ & $32.5(53)$ & $30.4(7)$ \\
1 & $31.0(27)$ & $41.0(67)$ & $26.1(6)$ \\
2 & $11.5(10)$ & $18.4(30)$ & $4.4(1)$ \\
$\quad 1.2(1)$ & $8.0(13)$ & $60.9(14)$ \\
How often do you give 'mutis'? & $59.8(52)$ & $47.2(77)$ & $26.1(6)$ \\
$\quad$ Never & $9.2(8)$ & $23.2(38)$ & $13.0(3)$ \\
$\quad$ Daily/weekly & $31.0(27)$ & $29.5(48)$ & \\
$\quad$ More than once per day or when needed &
\end{tabular}

Education level: 1 - low (both parents completed 10 years of schooling); 2 - middle (one parent completed 10-12 years of schooling and the other 7-12 years); 3 - high (one parent completed 10-12 years of schooling plus tertiary education and the other at least 12 years of schooling).

up to $25 \%$ of the children below 2 years of age could have been born in a rural area ${ }^{5}$.

Income, education and occupation are often used as a proxy for studying the effects of social class on disease among both rural and urban communities. However, these may not be appropriate as the majority of participants may be unemployed and have low education level. It may be more appropriate for future studies in such areas to use more sensitive indicators such as the type of building material used for the house or the possession of material objects such as a television or car $^{26}$. Social class indicators change over time and the classes vary in relation to each other and to health outcomes. In rapidly developing urban areas this is particularly important, since moves from rural to urban areas as well as within urban areas may improve family income and yet still result in individuals being poor $^{5}$. Most of the participants in the northern suburbs of Johannesburg and Sandton were domestic workers whose children were probably born in Soweto. Their personal income is therefore not a true reflection of that in the northern suburbs (R80 000), but would still be greater than the income of people from Soweto.

\section{Sugar use with comforter}

The study showed urbanisation to be associated with the use of sugar with the child's comforter. Urbanisation is associated with higher income, more employment and easier access and availability of foodstuffs such as sugar ${ }^{5}$. In the present study the use of comforters per se was not established. More than $90 \%$ of the mothers in the rural group indicated that they did not add sugar to the child's comforter and it is assumed that most of these mothers did not use comforters (personal observation). An earlier study in South Africa in $1984^{27}$ showed that $87 \%$ of rural black children and approximately $93 \%$ of the urban black children had never used comforters, with only $1 \%$ in both areas using comforters that were sweetened. The use of sweetened comforters in the present study was much higher in both urban groups.

\section{Use of bottle}

Urbanisation has led to improved and more accessible education $^{5}$. A greater awareness and understanding of the dangers of nursing bottles in promoting caries results in improved dietary habits in feeding young children. This holds true in explaining the higher percentage of rural mothers than urban Sowetan mothers putting their children to sleep with a bottle, but not for the urban Johannesburg group, who showed a high percentage (23\%) of children being put to sleep frequently with a bottle. An earlier study in the USA found that 20\% of the children aged between 6 months and 5 years were put to sleep with a bottle ${ }^{28}$. This figure is similar to the $23 \%$ of urban Johannesburg children put to sleep frequently with a bottle in the present study. Education level of the caretaker, race and geographic region were also found to be associated with differences in bottle feeding practices in Kaste and Gift's ${ }^{28}$ study, but not in the present one. Urbanisation has also resulted in higher employment ${ }^{5}$. More mothers in the urban environments are now working. In the evenings when the child is perhaps distressed and tired, the mother has very little time to devote to feeding the child herself and the easiest solution is to satisfy the child with a bottle. In the 1984 South African study ${ }^{27}$ it was found that $69.8 \%$ and $65 \%$ of the rural and urban black South African children, respectively, never had a sweetened drink in a feeding bottle. The present study showed a lower percentage of both rural (28\%) and urban (17\% and 25\%) children being put to sleep with a bottle than the 1984 study. This is a very positive aspect, indicating an increased awareness of the dangers of nursing bottles caries among all groups over the past 16 years and not only the urban groups. It must be remembered though that probably a high percentage of 
the rural mothers who indicated that they did not put their child to sleep with a bottle may not use a bottle at all.

\section{Breast-feeding}

Infant feeding choices are influenced by social and cultural factors, as reflected in sociodemographic correlates of breast-feeding, which show consistently low breast-feeding rates among women from low-income populations $^{29}$. In Africa and in most developing populations, despite the greater need for breast-feeding, the practice is tending to decrease, especially among urban mothers ${ }^{30,31}$. While the most common reasons given concern insufficiency of breast milk and employment of mothers, the urban mothers are under increasing pressure to use proprietary replacement foods ${ }^{30,31}$. The combination of restricted access to resources and inherent inefficiencies in their use determine the health and nutritional situation of people ${ }^{32}$. In addition, a dissatisfied baby or a baby who refuses milk, maternal illness, infant prematurity and the inadequacy of health services all contribute to the cessation or avoidance of breastfeeding ${ }^{30,31}$. Currently a huge adverse factor is the danger of human immunodeficiency virus (HIV) transference from seropositive mothers to infants ${ }^{31}$. In Southern Africa the proportions of antenatal mothers infected are believed to be the highest in the world, but a crucial factor in the situation described is that most mothers who are infected with HIV are unaware of their condition ${ }^{33-35}$. Regarding the present study, it is possible that the urban mothers in the Johannesburg area were more aware and better educated regarding transmission of the HIV virus from mother to child than the Soweto mothers, and opted for safety in stopping or not breast-feeding. It will be apparent that the outlook for breast-feeding in the 21st century, a practice so important for the health of infants in largely impoverished African populations, depends on many factors perhaps the most important of which is the control of HIV infection and its level of transmission ${ }^{31}$.

It was noted that, in this rural area in KwaZulu/Natal, it was common practice to give solid food first and then the breast. The solid food satisfied the child and he/she was then unwilling to take the breast ${ }^{36}$. Maternal age and maternal employment were found to be significantly associated with cessation of breast-feeding among Cape Town mothers ${ }^{37}$. A study carried out in Venda in 1990 on breast-feeding and weaning practices found that nearly all of the children under 2 years were breast-fed and virtually all of these were fed on demand ${ }^{38}$.

The 1984 study in South Africa ${ }^{27}$ found that almost 92\% of both the rural and urban black communities were breast-fed. By the time these children were 30 months old, $10.6 \%$ of the rural and only $4.6 \%$ of the urban groups were breast-fed. The majority of both the rural (33.3\%) and urban groups (22\%) were breast-fed for 18-24 months. In their study in the same areas of South Africa as the 1984 study, Roberts et al. ${ }^{7}$ also found that over $92 \%$ of the rural and urban black groups were breast-fed. Most of the rural mothers breast-fed for 18-24 months as well, while most of the urban mothers breast-fed for slightly less, 12-18 months. The present study found that over $70 \%$ of mothers breast-fed their children for the first 12 months. This decreased to approximately $10 \%$ by the age of 24 months for the rural and urban Soweto groups, with only $3 \%$ of the urban Johannesburg mothers breast-feeding at 24 months (Table 4).

The time of breast-feeding should be interpreted with caution, as it was difficult for mothers, in the rural area in particular, to put a time on how long they breast-fed. In the rural area the child is breast-fed on demand and the breast is often used as a comforter. The question 'How long is your child breast-fed for?' appeared to confuse the mothers, particularly in the rural area, and they tended not to answer this question, but it has been noted that breast-feeding is usually continued until the child is satisfied.

North et al. ${ }^{14}$, in their study on infants from the Avon Longitudinal Study of Pregnancy and Childhood in the UK, found that educational level was the most influential sociodemographic factor that explained the difference in consumption of various drinks at 8 months. Mothers with lower educational levels were more likely to have introduced cordials, hot drinks and cow's milk into their child's diet, while mothers with a higher educational level were more likely to have fed breast milk. Mills and Tyler ${ }^{39}$

Table 4 Mean age (standard deviation) in years and percentage of children being breast-fed, by rural/urban location and age group category

\begin{tabular}{lllll}
\hline \multicolumn{4}{c}{ Age group category } \\
\cline { 2 - 3 } & $4-12$ months & $13-18$ months & $19-24$ months & Total \\
\hline Rural $(n=105)$ mean decimal age & $0.94(0.534)$ & & \\
Yes & $79.0(n=45)$ & $10.5(n=6)$ & $10.5(n=6)$ & $100(n=57)$ \\
No & $48.9(n=23)$ & $23.4(n=11)$ & $27.7(n=13)$ & $100(n=47)$ \\
Urban Soweto $(n=100)$ mean decimal age $1.08(0.528)$ & & \\
Yes & $71.4(n=40)$ & $16.1(n=9)$ & $12.5(n=7)$ & $100(n=56)$ \\
No & $39.0(n=16)$ & $17.1(n=7)$ & $43.9(n=18)$ & $100(n=41)$ \\
Urban Johannesburg $(n=101)$ & mean decimal age 1.07 $(0.584)$ & \\
Yes & $79.0(n=30)$ & $18.4(n=7)$ & $2.6(n=1)$ & $100(n=38)$ \\
No & $36.5(n=23)$ & $34.9(n=22)$ & $28.6(n=18)$ & $100(n=63)$ \\
\hline
\end{tabular}


noted that mothers from higher socio-economic groups used more breast milk than the lower group, in a similar way to the comparison between the higher and lower educated groups in North and Emmett's ${ }^{40}$ study. The present study also found that mothers from higher social classes breast-fed more frequently than mothers from the lower social classes. Breast-feeding was also strongly correlated with education level of the mother among children participating in the Leiden Preschool Study in The Netherlands ${ }^{41}$. Mothers with higher education levels also breast-fed for longer and gave their children fewer sweets and snacks at 16 months, but the influence of education level disappeared at 28 months ${ }^{42}$.

\section{'Mutis' (common and traditional medicines)}

A higher education level is generally associated with a higher income and a broader knowledge of medicines, resulting in the purchase of 'mutis'. But it is also the custom or tradition among the rural community, a community generally with a low income and low education level, to give 'mutis'. This is passed down through the generations and they tend to adhere to traditional customs and beliefs. The rural group is vulnerable to diseases and infection, and has a greater need for medication than the urban group. Access to clinics in the rural environment may be difficult and mothers are more reliant on home remedies or over-the-counter medicines. These factors accounted for a higher percentage of rural mothers giving 'mutis' and more frequently than the urban mothers. This is supported when the number of mothers giving 'mutis' was combined with the frequency: $74(70 \%)$ of the rural mothers gave 'mutis' while only 37 (37\%) and 35 (35\%) of the urban Soweto and urban Johannesburg mothers, respectively, gave 'mutis'.

\section{Conclusions}

The study showed a strong influence of rural/urban environment on specific cariogenic food habits among very young black South African children. In addition, family customs, social class, education level and currently the adverse factor of the danger of human immunodeficiency virus (HIV) transference from seropositive mothers to their infants are likely to influence the dietary habits of these children, either directly or indirectly. In South Africa, urbanisation among the black population occurs very rapidly. It is essential to gain insight and knowledge of how urbanisation influences the dietary habits of the population, which will ultimately affect their nutritional status.

This study has provided valuable information on the cariogenic food habits of young children from a country that is in transition. The present study showed contrasting results with earlier studies and it is likely that the transitional changes may be responsible for this observation. Continuous surveillance of the dietary habits of young children is needed to evaluate the effect of urbanisation.

\section{Policy conclusion}

The identification and recognition of the effects of urbanisation and other socio-economic factors on the eating habits of young South African children will provide information for the South African Government to develop and implement a nutrition strategy targeting children. This is currently being debated.

\section{Acknowledgements}

The study was funded by the South African Sugar Association. We sincerely appreciate the nutrition monitors and interviewers for completing the questionnaires and coding the data; the parents who participated in the study; and Professor P.E. Cleaton-Jones for his assistance in analysing the data.

\section{References}

1 Stephens C. The urban environment, poverty and health in developing countries. Health Policy Plan 1995; 10: 109-121.

2 Fowler HW, Fowler FG, eds. Concise Oxford Dictionary of Current English, 5th ed. Oxford: Oxford University Press, 1975.

3 Rossi-Espagnet A. Primary Health Care in Urban Areas: Reaching the Urban Poor in Developing Countries. A State-of -the-Art Report by UNICEF and WHO SHS/84.4. Geneva: World Health Organization, 1984.

4 Van de Graaf JF. The Present State of Urbanisation in the South African Homelands: Rethinking the Concepts and Predicting the Future. Cape Town: Congress of the Development Society of Southern Africa, 1986.

5 Yach D, Matthews C, Buch E. Urbanisation and health: methodological difficulties in undertaking epidemiological research in developing countries. Soc. Sci. Med. 1990; 31: 507-14.

6 van Wyk PJ, ed. National Oral Health Survey South Africa 1988/89. Pretoria: Department of Health, 1994.

7 Roberts GJ, Cleaton-Jones PE, Richardson BD, Sinwel RE, Lucas VS. Breast and bottle feeding in rural and urban South African children. J. Hum. Nutr. Diet. 1995; 8: 255-63.

8 Dannhauser A, Bester CJ, Joubert G, Badenhorst PN, Slabber M, Badenhorst AM, et al. Nutritional status of preschool children in informal settlement areas near Bloemfontein, South Africa. Public Health Nutr. 2000; 3: 303-12.

9 Harpham T, Stephens C. Urbanisation and health in developing countries. World Health Statist. Quart. Rapp. 1991; 44: 62-9.

10 Solomons NW, Gross R. Urban nutrition in developing countries. Nutr. Rev. 1995; 53(4 Pt1): 90-5.

11 Adegbola $O$. The impact of urbanisation and industrialisation on health conditions: the case of Nigeria. World Health Statist. Quart. Rapp. 1987; 40: 74-83.

12 Yach D, Seager J, Watermeyer G. Understanding the global context of urbanisation and health in South Africa. S. Afr. Med.J. 1991; 79: 413-4.

13 Johnson RK, Guthrie H, Smiciklas-Wright H, Wong MQ. Characterising nutrient intakes of children by sociodemographic factors. Public Health Rep. 1994; 109: 414-20.

14 North K, Emmett P, Noble S, the ALSPAC Study Team. Types of drinks consumed by infants at 4 and 8 months of age: 
sociodemographic variations. J. Hum. Nutr. Diet. 2000; 13 $71-82$.

15 White Paper for the Transformation of the Health System in South Africa. Government Gazette 1997; 382(17910): 84-96.

16 Strategic Metropolitan Development Framework (SMDF) Global Context [Online]. Available at http://www.joburg. org.za/dsimp/html/Development.htm. Accessed 19 October 1999.

17 Schachtele CF, Jensen ME. Can foods be ranked according to their cariogenic potential?. In: Guggenheim B, ed. Cariology Today. Basel: S. Karger AG, 1984; 136-46.

18 Office of Population Censuses and Surveys. Classification of Occupations. London: Her Majesty's Stationery Office, 1980

19 Schlemmer L, Stopforth P. A Guide to the Coding of Occupations in South Africa. Fact Paper No. 4. Durban: University of Natal, Centre for Applied Social Sciences, 1979.

20 MacIntyre UE, Kruger HS, Venter CS, Vorster HH. Dietary intakes of an African population in different stages of transition in the North West Province, South Africa: the THUSA study. Nutr. Res. 2002; 22: 239-56.

21 Faber M, Oelofse A, Benade AJS. A model for a community based growth monitoring system. Afr. J. Health Sci. 1998; 5: $72-8$.

22 Langenhoven ML, Kruger M, Gouws E, Faber M. Research Institute for Nutritional Diseases (RIND) Food Composition Tables, 3rd ed. Cape Town: South African Medical Research Council, 1991

23 SAS Institute, Inc. SAS/STAT User's Guide Version 6, 4th ed. Vol. 1. Cary, NC: SAS Institute, Inc., 1989.

24 Khan MN, Cleaton-Jones PE. Dental caries in African preschool children: social factors as disease markers. Public Health Dent. 1998; 58: 7-11.

25 MacGuire A. Problem areas in oral medication. In: RuggGunn AJ, ed. Sugarless - Towards the Year 2000. London: Royal Society of Chemistry, 1994; 43-59.

26 Abramson JH, Gofin R, Habib J, Pridan H, Gofin J. Indicators of social class: a comparative appraisal of measures for use in epidemiological studies. Soc. Sci. Med. 1982; 16: 1739-46.

27 Richardson BD, Sinwel R, Cleaton-Jones P, Granath L, MacKeown JM, Walker A, et al. Dietary habits. In: CleatonJones P, Granath L, Richardson BD, eds. Dental Caries, Nutrient Intake, Dietary Habits, Anthropometric Status, Oral Hygiene and Salivary Factors and Microbiota in South African Black, Indian and White 4-5-year-old Children. Cape Town: South African Medical Research Council (MRC), 1991; Ch. 4.

28 Kaste LM, Gift HC. Inappropriate infant bottle feeding. Status of the Healthy People 2000. Arch. Pediatr. Adolesc. Med. 1995; 149: 786-91.

29 Libbus MK. Perspectives of common breastfeeding situations: a known group comparison. J. Hum. Lact. 1992; 8: $199-203$.

30 Moodley J, Saitowitz R, Linley L. A review of the literature on breastfeeding - policy and research issues. S. Afr. Med.J. 1999; 89: 681-7.

31 Walker ARP, Adam FI. Breastfeeding in sub-Saharan Africa: outlook for 2000. Public Health Nutr. 2000; 3: 285-92.

32 Sevenhuysen GP. Nutrition related resource use in urban areas. Southeast Asian J. Trop. Med. Public Health 1992; 23(Suppl. 3): 77-83.

33 Amanor-Wilks D. Zimbabwe attempts to prevent health crisis. Lancet 1996; 347: 609.

34 Kuhn L, Matthews C, Fransman D, Dikweni L, Hussey G. Child feeding practices of HIV-positive mothers in Cape Town, South Africa. Aids 1999; 13: 144-6.

35 Wilkinson D, Floyd K, Gilks CF. Antiretroviral drugs as a public health intervention for pregnant HIV-infected women in rural South Africa: an issue of cost effectiveness and capacity. Aids 1998; 12: 1675-82.

36 Faber M, Oelefse A, Kriek JA, Benade AJS. Breastfeeding and complementary feeding practices in a low socio-economic urban and low socio-economic rural area. S. Afr. J. Food Sci. Nutr. 1997; 9: 43-51.

37 Power DJ, Willoughby W, de Waal RH. Breastfeeding in Cape Town. S. Afr. Med. J. 1979; 56: 718-21.

38 Zollner E, Carlier ND. Breastfeeeding and weaning practices in Venda, 1990. S. Afr. Med.J. 1993; 83: 580-3.

39 Mills A, Tyler H. Food and Nutrient Intakes of British Infants aged 6-12 months. London: HMSO, 1992.

40 North K, Emmett P. Multivariate analysis of diet among threeyear-old children and associations with sociodemographic characteristics. The Avon Longitudinal Study of Pregnancy and Childhood (ALSPAC) Study Team. Eur. J. Clin. Nutr. 2000; 54: 73-80.

41 Horst CH, Obermann-de Boer GL, Kromhout D. Type of milk feeding and nutrient intake during infancy. The Leiden Pre-School Children Study. Acta Paediatr. Scand. 1987; 76 $865-71$.

42 Hoffmans MD, Obermann-de Boer GL, Florack EJ, van Kampen-Donker M, Kromhout D. Energy, nutrient and food intake during infancy and early childhood. The Leiden Pre-School Children Study. Hum. Nutr. Appl. Nutr. 1986; 40 421-30. 